Multi-layered hybrid perovskites templated with carbazole derivatives: optical properties, enhanced moisture stability and solar cell characteristics Peer-reviewed author version

HERCKENS, Roald; VAN GOMPEL, Wouter; SONG, Wenya; Gélvez-Rueda, María C.; MAUFORT, Arthur; RUTTENS, Bart; D'HAEN, Jan; Grozema, Ferdinand; AERNOUTS, Tom; LUTSEN, Laurence \& VANDERZANDE, Dirk (2018)

Multi-layered hybrid perovskites templated with carbazole derivatives: optical properties, enhanced moisture stability and solar cell characteristics. In: Journal of Materials Chemistry A, 6(45), p. 22899-22908.

DOI: $10.1039 / C 8 T A 08019 D$

Handle: http://hdl.handle.net/1942/27720 
This is the version of this publication before editing. The edited version of this publication can be found at: https://doi.org/10.1039/C8TA08019D

This version is for personal academic use only and may not be distributed or copied in any way, shape or form without written consent by the authors. 
Received 00th January 20xx, Accepted 00th January 20xx

DOI: $10.1039 / x 0 x \times 00000 x$

www.rsc.org/

\title{
Multi-layered hybrid perovskites templated with carbazole derivatives: optical properties, enhanced moisture stability and solar cell characteristics
}

\author{
Roald Herckens ${ }^{a,{ }^{\dagger}}$, Wouter T.M. Van Gompel ${ }^{a,{ }^{\dagger}}$, Wenya Song ${ }^{b, c}$, María C. Gélvez-Rueda ${ }^{d}$, Arthur \\ Maufort $^{\mathrm{a}}$, Bart Ruttens ${ }^{\mathrm{e}}$, Jan D'Haen ${ }^{\mathrm{e}, \mathrm{f}}$, Ferdinand C. Grozema ${ }^{\mathrm{d}}$, Tom Aernouts ${ }^{\mathrm{c}}$, Laurence Lutsen $^{\mathrm{a}, \mathrm{e}}$, \\ Dirk Vanderzande ${ }^{\mathrm{a}, \mathrm{e}, *}$
}

\begin{abstract}
Research into 2D layered hybrid perovskites is on the rise due to the enhanced stability of these materials compared to 3D hybrid perovskites. Recently, interest towards the use of functional organic cations for these materials is increasing. However, a vast amount of the parameter space remains unexplored in multi-layered $(n>1)$ hybrid perovskites for solar cell applications. Here, we incorporate carbazole derivatives as a proof of concept towards the use of tailored functional molecules in multi-layered perovskites. Films of low- $n$ carbazole containing perovskites show high photoconductivity halflifetimes. Higher- $n(\langle n\rangle=40)$ multi-layered perovskite films possess charge carrier diffusion lengths comparable to MAPI thin films. Solar cells containing these materials have comparable efficiencies to our MAPI and phenethylammonium (PEA)containing multi-layered perovskite reference devices. Moisture stability tests were performed both at the material and device levels. In comparison to MAPI and PEA-based materials and solar cells, the addition of a small percentage of the carbazole derivative to the perovskite material significantly enhances the moisture stability.
\end{abstract}

\section{Introduction}

Hybrid organic-inorganic perovskite solar cells have received significant attention over the past years due to their interesting optoelectronic properties and their rapid increase in power conversion efficiency (PCE) up to $22.1 \%$ today. ${ }^{1}$ Threedimensional (3D) perovskite materials have mainly been studied due to the high efficiency of their solar cells. However, these materials generally exhibit an intrinsic instability and can degrade when exposed to moisture, heat, oxygen and/or light. ${ }^{2}$ Efforts to increase the stability have mostly focused on introducing other small cations such as formamidinium (FA) and caesium (Cs). Mainly the thermal stability of 3D perovskite materials has improved significantly via this methodology. ${ }^{2}$

A different approach to develop more resilient hybrid perovskite materials involves two-dimensional (2D) Ruddlesden-Popper phase layered perovskites. Interest in these multi-layered hybrid perovskites $\left(\left.A^{*}{ }_{2} \mathrm{~A}_{n-1} \mathrm{~Pb}_{n}\right|_{3 n+1}\right.$, with $A^{*}$ a large organic ammonium cation, $\mathrm{A}$ a small organic ammonium cation and $n$ the number of inorganic layers in the structure) for solar cell applications increased due to reports about their enhanced moisture stability compared to 3D hybrid

\footnotetext{
a. Hasselt University, Institute for Materials Research (IMO-IMOMEC), Hybrid Materials Design (HyMaD), Martelarenlaan 42, B-3500 Hasselt, Belgium. b. imec, Thin-Film Photovoltaics, Energyville, Thor Park 8320, B-3600 Genk, Belgium.

c. KU Leuven, ESAT, B-3001 Leuven, Belgium.

d. Delft University of Technology, Department of Chemical Engineering, Section Optoelectronic Materials, Van der Maasweg 9, 2629 HZ Delft, The Netherlands. e. imec, Associated Laboratory IMOMEC, Wetenschapspark 1, B-3590 Diepenbeek, Belgium.

f. Hasselt University, Institute for Materials Research (IMO-IMOMEC), Electrical and physical characterization (ELPHYC), Martelarenlaan 42, B-3500 Hasselt, Belgium. † These authors contributed equally

Electronic Supplementary Information (ESI) available: Details of the carbazole derivative synthesis, SEM pictures, additional UV-Vis absorption spectra, photoconductivity transients and optical pictures of films and solar cells. See DOI: $10.1039 / x 0 x x 00000 x$
}

perovskites. ${ }^{3-5}$ Although solar cells employing these materials are generally less performant compared to 3D hybrid perovskites, their PCEs have recently increased up to $12.5 \%$ by applying techniques such as 'hot-casting' (HC). ${ }^{6-12}$ One of the major advantages of the 2D layered perovskite over the 3D perovskite is the structural tolerance towards larger and more complex organic cations. ${ }^{12-14}$ Although it has been shown that a variety of organic cations ${ }^{13-15}$ can be used to obtain 2D-layered perovskites $\left(\mathrm{A}_{2}{ }_{2} \mathrm{PbX}_{4} ; n=1\right)$, a vast amount of this parameter space remains unexplored in multi-layered $(n>1)$ hybrid perovskites for solar cell applications. Until now mainly small alkylic and benzylic cations have been applied in such multi-layered perovskites (e.g. butylammonium ${ }^{7}$, iso-butylammonium ${ }^{16}$, phenethylammonium ${ }^{17,18}$, anilinium $^{19}$, cyclohexylammonium ${ }^{18}$, benzylammonium ${ }^{18,20}$, propylphenylammonium ${ }^{20}$, guanidinium ${ }^{21}$ and allylammonium ${ }^{22}$ ). The main advantages of these multi-layered hybrid perovskites over their $n=1$ counterparts are a lower exciton binding energy and a smaller band gap, which is beneficial towards their use in solar cell applications. ${ }^{7,17}$ Moreover, multi-layered perovskites possess tuneable properties - such as absorption and emission - depending on the number of inorganic layers $(n)$ in the structure.7,12,17 We incorporated bulkier, more complex, carbazole (CA) derivatives containing an extended $\pi$-conjugated system as a first proof-ofconcept towards the introduction of tailored functional organic molecules in multi-layered perovskites for solar cell applications. Beyond the field of perovskite materials, carbazole-based polymers/semiconductors have primarily attracted attention for their photoconductive properties. ${ }^{23}$ In the context of perovskite, carbazole derivatives have been used in a fundamental study on the synthesis of 2D layered perovskites $\left(\left(C A-C_{m}\right)_{2} \mathrm{PbBr}_{4}\right)$, where derivatives with different lengths of alkyl spacer $(m)$ were examined towards the formation of the $n=1$ layered structure. ${ }^{24,25}$ Although this $n=1$ layered perovskite is not suitable as a material for solar cells, it exhibited an interesting increase of the in-plane conductivity in comparison to both polyvinylcarbazole polymers and layered perovskites with hexylammonium (an insulator) as an organic layer. ${ }^{24}$ 
Carbazole derivatives are therefore a prime choice of an extended $\pi$ conjugated organic molecule to be introduced in functional multilayered $(n>1)$ perovskites for photovoltaic applications.

In this work, carbazole-based organic cations were synthesised with an alkyl-spacer length $(m)$ of four $\mathrm{CH}_{2}$ groups. These organic cations were used to obtain lead iodide $\left(\mathrm{Pbl}_{2}\right)$ based multi-layered perovskites with methylammonium (MA) as small organic cation $\left(\left(C A-C_{4}\right)_{2} M A_{n-1} P b_{n} I_{3 n+1}\right)$. The formation and the structure of the multilayered and quasi-3D perovskites incorporating carbazole were investigated. Films of low- $n$ carbazole containing perovskites show high photoconductivity half-lifetimes in comparison to films of established butylammonium based, low- $n$ multi-layered perovskites. Higher- $n(\langle n\rangle=40)$ multi-layered perovskite films possess charge carrier diffusion lengths comparable to MAPI thin films. It was found that the moisture stability of the carbazole containing perovskites is superior compared to the reference MAPI and PEA-based perovskites. Likewise, the moisture stability of the corresponding solar cell devices was significantly improved while maintaining a similar initial power conversion efficiency.

\section{Experimental}

\section{Chemicals and reagents}

Lead iodide (PbI2, $99.999 \%$ ) was either obtained from Lumtec or from $\mathrm{TCl}$ (99.99\%) and used without further purification. Methylammonium iodide was obtained from GreatCell Solar. Hydroiodic acid (HI, 57 \% w/w aq., distilled, unstabilised) and phenethylamine (PEA, 99\%) were purchased from Acros Organics and used as received. Carbazole (96\%), potassium tert-butoxide $(98+\%)$, hydrazine monohydrate $(65 \%)$ and all solvents used for synthesis (reagent grade) were purchased from Fisher Scientific. Potassium phthalimide salt (95\%) was purchased from Fluorochem. The $\mathrm{SnO}_{2}$ water dispersion (15 wt\%) was purchased from Alfa Aesar and was diluted to $2.5 \mathrm{wt} \%$ for use. Spiro-OMeTAD was obtained from Lumtec. Lithium bis(trifluoromethanesulfonyl) imide, 4-tertbutylpyridine, dimethylformamide, acetonitrile and chlorobenzene were obtained from Sigma Aldrich.

\section{Synthesis of organic ammonium salts}

The synthesis of the carbazole alkylammonium iodide derivatives (CA- $\mathrm{C}_{4}-\mathrm{NH}_{3} \mathrm{l}$, shortened to $\mathrm{CAl}$ ) is detailed in the supporting information (Figure S1). Phenethylammonium iodide (PEAI) was synthesised by neutralizing equimolar amounts of hydroiodic acid $(\mathrm{HI}, 57 \% \mathrm{w} / \mathrm{w})$ and phenethylamine at $0{ }^{\circ} \mathrm{C}$ in an ice bath. An offwhite precipitate was obtained by evaporation of the solvent using rotary evaporation at $70{ }^{\circ} \mathrm{C}$ under reduced pressure. The resulting precipitate was recrystallised three times from ethanol, washed with diethylether and dried overnight under reduced pressure at room temperature.

\section{Thin film deposition and annealing}

Precursor solutions were prepared according to the nominal structural formula $\left(\mathrm{CA}-\mathrm{C}_{4}\right)_{2} \mathrm{MA}_{\mathrm{n}-1} \mathrm{~Pb}_{n} \mathrm{I}_{3 \mathrm{n}+1}$ (Table 1). Stoichiometric amounts of $\mathrm{CAl}, \mathrm{MAl}$ and $\mathrm{Pbl}_{2}$ were dissolved in dry dimethylformamide (DMF) at $70{ }^{\circ} \mathrm{C}$ for $1 \mathrm{~h}$ under constant stirring. The resulting clear solutions were filtered through a syringe filter (0.45 $\mu \mathrm{m}$ pore size).
Quartz substrates were cleaned through consecutive sonication steps in a series of solvents (detergent water, deionised water, acetone, isopropanol) for $15 \mathrm{~min}$ each, followed by a UV-ozone treatment for $30 \mathrm{~min}$.

Films for optical measurements, TRMC and XRD analysis were deposited on quartz substrates using spin coating in a glovebox with

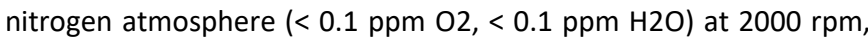
$2000 \mathrm{rpm} / \mathrm{s}$ for $20 \mathrm{~s}$. Annealing was performed via hot-casting (HC) or by post-annealing on a hotplate in the glovebox, the annealing temperature differs for different $\langle\mathrm{n}\rangle$ and is indicated in the relevant figure captions. Prepared samples were kept in a glovebox and were only removed for analysis.

Table 1. Composition of precursor solutions for different $\langle n\rangle$

\begin{tabular}{|c|l|l|l|l|}
\hline$<n>$ & $\begin{array}{l}\text { Nominal } \\
\text { thuctural } \\
\text { formula }\end{array}$ & $\begin{array}{l}\mathrm{Pbl}_{2} \\
\text { concentra } \\
\text { tion } \\
(\mathrm{mol} / \mathrm{l})\end{array}$ & $\begin{array}{l}\text { MAl } \\
\text { concentra } \\
\text { tion } \\
(\mathrm{mol} / \mathrm{l})\end{array}$ & $\begin{array}{l}\text { CAl/PEAl } \\
\text { concentra } \\
\text { tion } \\
(\mathrm{mol} / \mathrm{l})\end{array}$ \\
\hline 1 & $\mathrm{CA}_{2} \mathrm{Pbl}_{4}$ & 0.3 & 0 & 0.6 \\
\hline 2 & $\mathrm{CA}_{2} \mathrm{MAPb}_{2} \mathrm{I}_{7}$ & 0.3 & 0.15 & 0.3 \\
\hline 3 & $\mathrm{CA}_{2} \mathrm{MA}_{2} \mathrm{~Pb}_{3} \mathrm{l}_{10}$ & 0.3 & 0.2 & 0.2 \\
\hline 4 & $\mathrm{CA}_{2} \mathrm{MA}_{3} \mathrm{~Pb}_{4} \mathrm{I}_{13}$ & 0.3 & 0.225 & 0.15 \\
\hline 10 & $\mathrm{CA}_{2} \mathrm{MA}_{9} \mathrm{~Pb}_{10} \mathrm{l}_{31}$ & 0.3 & 0.27 & 0.06 \\
\hline 40 & $\mathrm{CA}_{2} \mathrm{MA}_{39} \mathrm{~Pb}_{40} \mathrm{l}_{121}$ & 0.3 & 0.2925 & 0.015 \\
\hline 40 & $\mathrm{PEA}_{2} \mathrm{MA}_{39} \mathrm{~Pb}_{40} \mathrm{O}_{121}$ & 0.3 & 0.2925 & 0.015 \\
\hline$\infty$ & $\mathrm{MAPbl}_{3}$ & 0.3 & 0.3 & N.A. \\
\hline
\end{tabular}

\section{Device fabrication}

Devices were made in an ITO/SnO $2 /$ perovskite/Spiro-OMeTAD/Au configuration. The ITO-coated glass substrates were successively cleaned in ultrasonic baths containing detergent water, deionised water, acetone and isopropanol for 5 min, respectively. Afterwards, these cleaned substrates were treated with oxygen plasma. A 2.5 wt\% water dispersion of $\mathrm{SnO}_{2}$ nanoparticles was then spin coated on the substrates at $2800 \mathrm{rpm}$ and pre-heated at $110{ }^{\circ} \mathrm{C}$. Perovskite solution in DMF was spin coated on these heated substrates at 3000 rpm for $60 \mathrm{~s}$, followed by annealing at $110{ }^{\circ} \mathrm{C}$ for $15 \mathrm{~min}$. An 80 $\mathrm{mg} / \mathrm{mL}$ Spiro-OMeTAD solution doped with $17.5 \mu \mathrm{l}$ lithium bis(trifluoromethanesulfonyl) imide (Li-TFSI) $\quad(520 \mathrm{mg} / \mathrm{mL}$ in acetonitrile) and $28.5 \mu \mathrm{L}$ 4-tert-butylpyridine was then spin coated onto the perovskite films. These films were exposed overnight to air with $26 \%$ relative humidity $(\mathrm{RH})$ for oxygen doping. Finally, the devices were completed by depositing an $80 \mathrm{~nm}$ Au layer onto the Spiro-OMeTAD through a shadow mask, defining an active area of $0.13 \mathrm{~cm}^{2}$

\section{Characterization}

X-ray diffraction measurements were performed at room temperature in ambient atmosphere on a Bruker D8 Discover diffractometer with $\mathrm{CuK}_{\alpha}$ radiation.

Optical absorption spectra were measured on a Cary 5000 UV-VisNIR spectrophotometer from Agilent Technologies, a cleaned quartz substrate was used as calibration background.

Photoluminescence emission spectra were taken with a Horiba-Jobin Yvon Fluorolog-3 spectrofluorometer, equipped with double-grating excitation and emission monochromators and a $450 \mathrm{~W}$ Xe lamp as a 
light source. An excitation wavelength of either $300 \mathrm{~nm}$ or $430 \mathrm{~nm}$ was used (as indicated in the corresponding figure captions).

SEM measurements were performed on a FEI Quanta 200F.

Laser induced time-resolved microwave conductivity (TRMC) measurements 26,27 were performed on thin films of CA- $\mathrm{C}_{4}$ multilayered perovskites (with $\langle n\rangle=1,2,3,4,10$ or 40 ) deposited on quartz substrates and placed in a sealed resonant cavity inside a nitrogen-filled glovebox. The TRMC technique measures the change in microwave $(8-9 \mathrm{GHz})$ power upon pulsed excitation (repetition rate $10 \mathrm{~Hz}$ ) of the thin films (the excitation wavelengths used are indicated in the relevant figure captions). Before and during the photo-conductance measurements, the samples were kept in an inert nitrogen environment to prevent possible degradation by exposure to moisture.

\section{Results and discussion}

\section{Formation and structure}

The synthesis of the series of functionalized 2D multi-layered perovskites featuring carbazole derivatives was achieved by mixing stoichiometric ratios of CAl, MAl and $\mathrm{Pbl}_{2}$ in DMF. These solutions were spin-coated and subsequently annealed to obtain the desired perovskites.

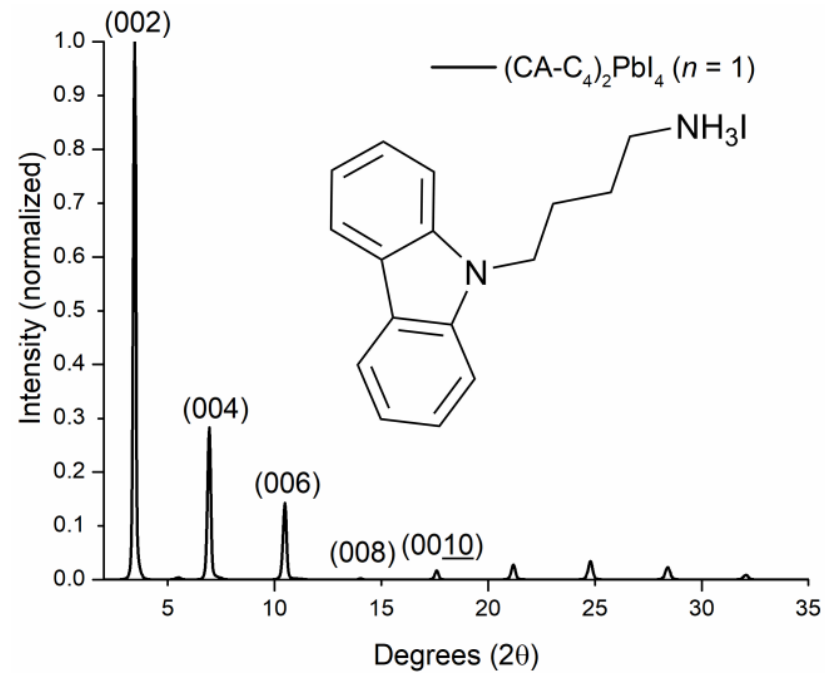

Figure 1. X-ray diffraction pattern of a $\left(\mathrm{CA}-\mathrm{C}_{4}\right)_{2} \mathrm{Pbl}_{4}(n=1)$ film obtained by post-annealing at $110^{\circ} \mathrm{C}$ for $15 \mathrm{~min}$. The structure of the CA- $C_{4}$ ammonium salt is shown as an inset. The reflections were indexed tentatively based on ref. ${ }^{28}$

As a starting reference, the $n=1\left(\left(\mathrm{CA}-\mathrm{C}_{4}\right)_{2} \mathrm{Pbl}_{4}\right)$ was obtained as a thin-film. The diffraction pattern (Figure 1 ) consists of a series of $(00$ l) reflections characteristic for a $n=1$ layered $2 \mathrm{D}$ perovskite with preferential growth along the $\left(\begin{array}{ll}1 & 1\end{array}\right)$ ) direction, such that the organic layers are oriented parallel to the substrate. ${ }^{28}$ The reflections are indexed tentatively based on similarity with literature 2D layered perovskites. ${ }^{28}$ An interplanar spacing $\left(\mathrm{d}_{00 /}\right)$ of $\sim 25.5 \AA$ is obtained (Table S1). This matches well with two times the length of the carbazole molecule $(\sim 12 \AA)$, indicating that a bilayer of these molecules is present in the structure as expected for a $2 \mathrm{D}$ layered perovskite.
When multi-layered perovskites are targeted, $\langle n\rangle=2,\langle n\rangle=3,\langle n\rangle$ $=4,\langle n\rangle=10$ and $\langle n\rangle=40$ will be used to denote the nominal composition that is targeted based on the stoichiometry of the precursor solution and $n$ will be used to denote the multi-layered $\left(\mathrm{CA}-\mathrm{C}_{4}\right)_{2} \mathrm{MA}_{n-1} \mathrm{~Pb}_{n} \mathrm{I}_{3 \mathrm{n}+1}$ perovskite with that specific number of layers $(n)$ as identified. It is important to note however that for a targeted $\langle n\rangle$, a mixture of layered perovskites with a different number of layers $(n)$ are generally present in thin-film. This has been frequently reported in literature for multi-layered perovskites starting from different large organic molecules $\left(A^{*}\right) .{ }^{29-31}$ For example, Sargent et al. showed, using transient absorption spectroscopy, that a film nominally prepared as $\langle n\rangle=3$ using PEAl contains signatures of $n=$ $2,3,4$ and 5 phases. ${ }^{29}$

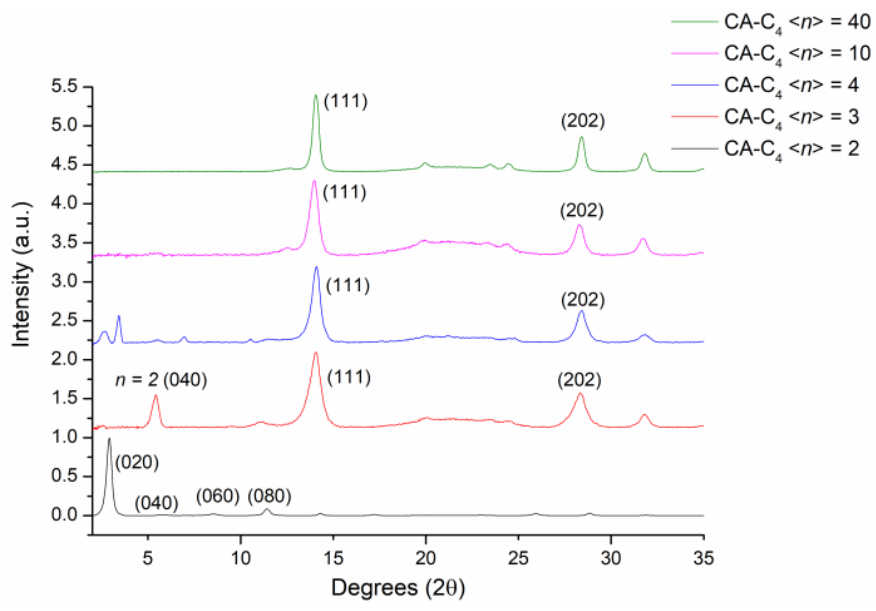

Figure 2. X-ray diffraction patterns of films based on $\mathrm{CA}-\mathrm{C}_{4}$ with different $\langle n\rangle$. The $\langle n\rangle=2$ film was obtained by post-annealing at 150 ${ }^{\circ} \mathrm{C}$ for $15 \mathrm{~min}$. The $\langle n\rangle=3$ film was obtained by post-annealing at 130 ${ }^{\circ} \mathrm{C}$ for $15 \mathrm{~min}$. The $\langle n\rangle=4,10$ and 40 films were hot-cast at $110^{\circ} \mathrm{C}$. The broad diffraction band from $\sim 16^{\circ}-30^{\circ} 2 \theta$ corresponds to diffraction of the underlying quartz substrate ${ }^{32}$ (Figure S2). The main reflections for the multi-layered perovskites containing the carbazole derivative were indexed tentatively based on ref. ${ }^{28}$

In thin films of multi-layered $\langle n\rangle=2$ perovskites, $(0 \mathrm{k} 0)$ reflections which are present characteristic ${ }^{28}$ for a $n=2$ layered perovskite with the organic layer oriented parallel to the substrate (Figure 2). An interplanar spacing $\left(\mathrm{d}_{0 \mathrm{k} 0}\right)$ of $\sim 30.8 \AA$ is obtained for these reflections (Table S2). This is a difference of $\sim 5.3 \AA$ compared to the interplanar spacing of the $n=1$ perovskite, which approximately matches with the height of a single $\mathrm{Pbl}_{6}$ octahedron. ${ }^{33,34}$

For $\langle n\rangle=3$, the $\left(\begin{array}{lll}1 & 1 & 1\end{array}\right)$ and $\left(\begin{array}{lll}2 & 0 & 2\end{array}\right)$ reflections of the perovskite structure, respectively at $\sim 14^{\circ}$ and at $\sim 28^{\circ}$, become much more pronounced, indicating that the preferential growth direction is changing towards vertical growth. ${ }^{35}$ Small reflections at lower angles are also present indicative of the presence of other low- $n$ perovskites. For $\langle n\rangle=4$ different reflections below $10^{\circ} 2 \vartheta$ are present, which points to the presence of a complex mixture of multiple $n$ as can be deduced from the absorption and emission spectra (vide infra).

In literature, the hot-casting procedure has been applied for different multi-layered and 3D perovskites to improve the perovskite crystallinity, morphology and orientation. ${ }^{36,37}$ SEM pictures of thin films of $\mathrm{CA}-\mathrm{C}_{4}<n>=40$ show that the morphology for post-annealed 
films is needle-like ${ }^{38-40}$ and changes to planar structures with less pinholes for hot-casted films (Figure S3). The morphology of the hotcasted films is expected to be more suitable for solar cell devices. This hot-casting method was therefore applied on our material for the solar cell fabrication (vide infra).

For films of higher $<n>$ perovskites obtained using the hot-casting method $(\langle n\rangle=4,10$ and 40$)$, the $\left(\begin{array}{lll}1 & 1 & 1\end{array}\right)$ and $\left(\begin{array}{lll}2 & 0 & 2\end{array}\right)$ reflections dominate the diffraction pattern (Figure 2), indicating that, combined with the results of optical measurements (vide infra), mostly quasi-3D perovskites are obtained. The weak reflections between $\sim 20^{\circ}$ and $25^{\circ} 2 \vartheta$ are similar to those of bulk tetragonal $\mathrm{MAPbl}_{3}$, pointing to the presence of "quasi-3D" perovskites in these higher $<n>$ films. From the absorption and emission spectra of these films (vide infra) it is clear that the films still contain multi-layered perovskites with optical properties different from bulk $\mathrm{MAPbl}_{3}$.

For such quasi-3D perovskites it has been hypothesized that the organic molecules are present at the lattice surface and at grain boundaries of 3D perovskite grains. ${ }^{41}$

\section{Optical properties}

The excitonic absorption peaks and/or optical band gaps $\left(E_{g}\right)$ of the $\left(\mathrm{CA}-\mathrm{C}_{4}\right)_{2} \mathrm{MA}_{n-1} \mathrm{~Pb}_{n} \mathrm{I}_{3 n+1}$ were investigated (Figure 3). The absorption spectrum for the $n=1 \mathrm{CA}-\mathrm{C}_{4}$ perovskite contains clear signatures corresponding to absorption by the carbazole molecules (Figure S7) at low wavelengths, as well as an excitonic absorption peak at $\sim 494$ $\mathrm{nm}(2.51 \mathrm{eV})$. This is in the same energy region as the excitonic absorption peaks for other $n=1$ layered iodide hybrid perovskites reported in literature (e.g. $\sim 2.4 \mathrm{eV}$ for $\left.(\mathrm{PEA})_{2} \mathrm{Pbl}_{4}\right){ }^{34}$ It has been shown that the excitonic absorption peak position is mainly dependent on the distortion of the inorganic perovskite layer by the organic cation. 42,43

Going to higher $\langle n\rangle$, the excitonic absorption peaks shift towards lower energy (Figure 3, Table 2) due to decreased quantum confinement. ${ }^{44,45}$ The excitonic peak positions for the $n=2, n=3$ and $n=4$ multi-layered perovskite are assigned on the absorption spectrum of a CA- $C_{4}\langle n\rangle=3$ film in Figure S8. For $\langle n\rangle>2$ multiple excitonic peaks belonging to low- $n$ perovskites are clearly present in the spectra and for $\langle n>>3$ also a band gap at much lower energy ( $1.6 \mathrm{eV}$ ) is present (Table 3), indicative of the formation of quasi-3D perovskites together with the low- $n$ phases. Note that the band gap (and emission peak; Figure 4) belonging to the quasi-3D perovskites that are formed together with the low- $n$ phases also shifts to lower energy with increasing $\langle n\rangle$ (Table 3 ). This indicates that the quasi-3D part of the films contains progressively higher $n$ CA- $C_{4}$ perovskites when using higher $\langle n\rangle$ precursor stoichiometries. This matches well qualitatively with the results of the recent article by QuinteroBermudez et al. ${ }^{51}$

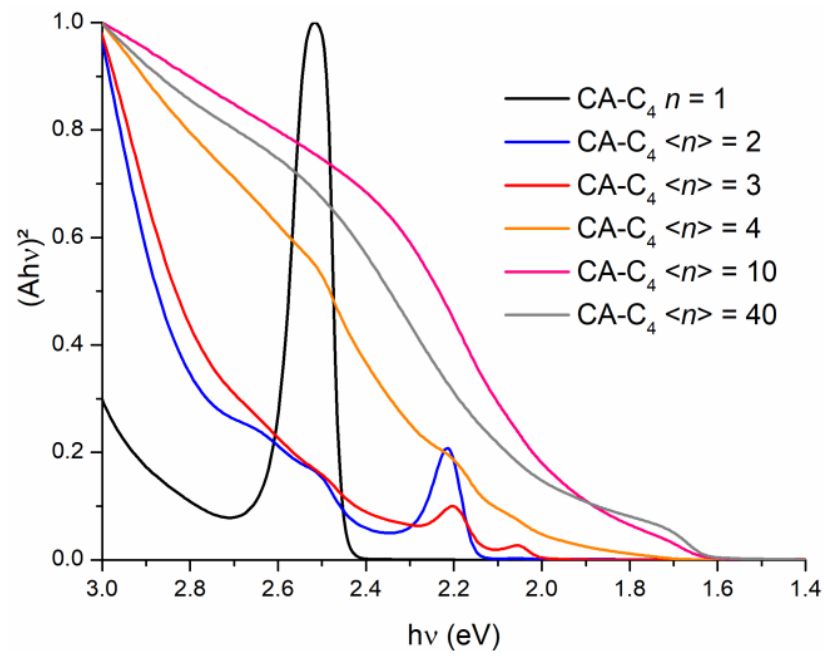

Figure 3. Tauc plots of $\mathrm{CA}-\mathrm{C}_{4}$ films with different $<n>$ obtained by post-annealing at $110{ }^{\circ} \mathrm{C}(\langle n\rangle=1), 130{ }^{\circ} \mathrm{C}(\langle n\rangle=3)$ and $150{ }^{\circ} \mathrm{C}(\langle n\rangle$ $=2$ ) for $15 \mathrm{~min}$. The $\langle n\rangle=4,10$ and 40 films were obtained using hotcasting at $110^{\circ} \mathrm{C}$. A zoomed-in version is shown in Figure $\mathrm{S} 5$ to more clearly distinguish the absorption onsets. The absorption spectra used to make the Tauc plots are shown in Figure S6.

Table 2. Excitonic absorption peak energies for multi-layered perovskites with different $n$.

\begin{tabular}{|l|c|c|}
\hline CA- $\mathrm{C}_{\mathrm{m}}$ & $n$ & $\begin{array}{c}\text { Excitonic } \\
\text { absorption peak } \\
\text { energy }(\mathrm{eV} / \mathrm{nm})\end{array}$ \\
\hline CA-C $_{4}$ & 1 & $2.51 / 494$ \\
\hline & 2 & $2.21 / 561$ \\
\hline & 3 & $2.06 / 602$ \\
\hline & 4 & $1.96 / 633$ \\
\hline
\end{tabular}

Table 3. Optical band gap energies for quasi-3D perovskites obtained for films from precursor solutions targeting different $\langle n\rangle$. A representative Tauc plot with tangent intersecting the energy axis is shown in Figure $\mathrm{S} 9$.

\begin{tabular}{|c|c|c|}
\hline CA- $C_{m}$ & $<n>$ & $\begin{array}{c}\text { Optical band gap } \\
\text { energy }(\mathrm{eV} / \mathrm{nm})\end{array}$ \\
\hline $\mathrm{CA}-\mathrm{C}_{4}$ & $4^{*}$ & $1.688 / 735$ \\
\hline & 10 & $1.626 / 763$ \\
\hline & 40 & $1.617 / 767$ \\
\hline
\end{tabular}

*Formed together with low-n perovskites (see Table 2)

The photoluminescence $(\mathrm{PL})$ emission spectra for these materials show similar trends as the absorption spectra. Going from lower to higher $\langle n\rangle$, the emission peaks shift towards lower energy (Figure 4, Table 4 and Table 5). Looking at the PL emission in the low wavelength region ( $320 \mathrm{~nm}-500 \mathrm{~nm}$ ) for $\mathrm{CA}_{-} \mathrm{C}_{4} n=1$, one notices the same emission peaks as for the $\mathrm{CA}-\mathrm{C}_{4}$ precursor salt (Figure $\mathrm{S} 10$ ). However, the relative intensities of these peaks are different. This can be related to the incorporation of the carbazole molecules into the perovskite structure. The excitonic emission peaks for the $n=1$ is located at $\sim 501 \mathrm{~nm}(2.47 \mathrm{eV})$. Hence, there is a small Stokes shift $(0.04 \mathrm{eV})$ between the excitonic absorption and emission peaks. For 
$n=1$, a broad emission feature at lower energy can be noticed that disappears for higher- $n$ CA- $C_{4}$ layered perovskites. Similar features in the emission spectra of $2 \mathrm{D}$ layered perovskites have been assigned to luminescence from self-trapped excitons or long-lived colour centers. ${ }^{46-48}$ Determining the origin of this broad emission feature goes beyond the scope of this article and is the subject of further work. For higher $\langle n\rangle$, emission peaks at lower wavelengths corresponding to quasi-3D perovskites are present (Table 5). From this analysis it is clear that we can tune the absorption and emission properties of the carbazole containing perovskites by changing the stoichiometry of the precursor solutions.

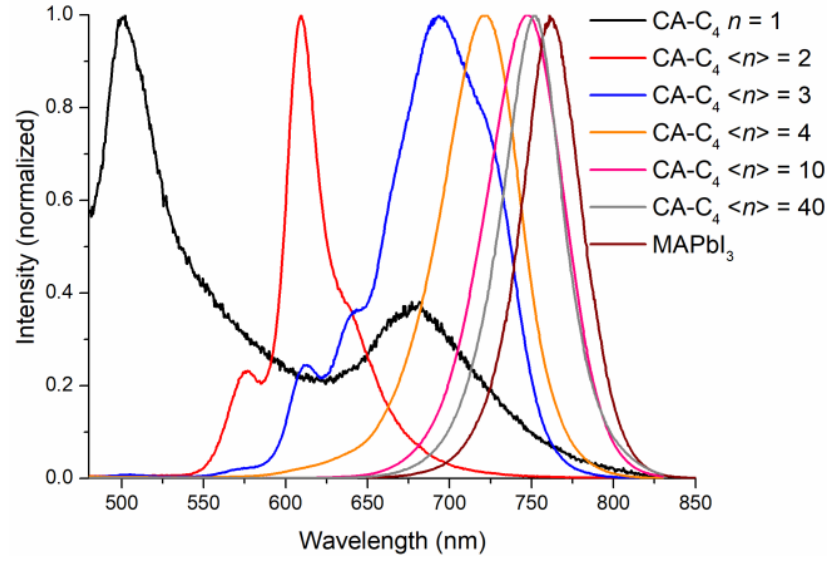

Figure 4. Photoluminescence emission spectra of $\mathrm{CA}^{-} \mathrm{C}_{4}$ films with different $\langle n\rangle$ obtained by post-annealing at $110{ }^{\circ} \mathrm{C}(n=1), 130{ }^{\circ} \mathrm{C}$ $(<n>=3)$ and $\left.150^{\circ} \mathrm{C}(<n\rangle=2\right)$ for $15 \mathrm{~min}$. The $<n>=4,10$ and 40 films and the MAPI film were obtained using hot-casting at $110{ }^{\circ} \mathrm{C}$. The samples were excited at $430 \mathrm{~nm}$.

Table 4. Excitonic emission peak energies for multi-layered perovskites with different $n$. The emission peaks are assigned on the emission spectra in Figure S11 for each $n$.

\begin{tabular}{|l|c|c|}
\hline $\mathrm{CA}^{-} \mathrm{C}_{\mathrm{m}}$ & $n$ & $\begin{array}{c}\text { Excitonic emission } \\
\text { peak energy } \\
(\mathrm{eV} / \mathrm{nm})\end{array}$ \\
\hline $\mathrm{CA}-\mathrm{C}_{4}$ & 1 & $2.47 / 501$ \\
\hline & 2 & $2.15 / 576$ \\
\hline & 3 & $2.03 / 610$ \\
\hline & 4 & $1.93 / 642$ \\
\hline
\end{tabular}

Table 5. Emission peak energies for quasi-3D perovskites obtained for films from precursor solutions targeting different $\langle n\rangle$. The emission peaks are assigned on the emission spectra in Figure S11 as “quasi-3D”.

\begin{tabular}{|l|c|l|}
\hline $\mathrm{CA}_{\mathrm{m}} \mathrm{C}_{\mathrm{m}}$ & $<n>$ & $\begin{array}{l}\text { Emission peak } \\
\text { energy of quasi } \\
3 \mathrm{D} \text { perovskites } \\
(\mathrm{eV} / \mathrm{nm})\end{array}$ \\
\hline $\mathrm{CA}^{-} \mathrm{C}_{4}$ & 3 & $1.79 / 694$ \\
\hline & 4 & $1.72 / 721$ \\
\hline & 10 & $1.66 / 748$ \\
\hline & 40 & $1.65 / 751$ \\
\hline
\end{tabular}

\section{Photoconductivity and charge-carrier dynamics}

To study the charge carrier dynamics of the carbazole and PEA multilayered perovskites we performed photo-conductivity measurements. Details on this technique and on the calculation of the charge carrier mobility, lifetime and diffusion lengths can be found in ref. ${ }^{26}$ In these measurements, the laser-induced change in conductivity of the material, $\Delta G$, is measured as a function of time. Typical conductivity measurements are shown in Figure 5 (a) for CA$C_{4}\langle n\rangle=40$ (for other $\langle n\rangle$ this is shown in Figure S12). $\Delta \mathrm{G}$ increases during the pulse as charge carriers are generated and subsequently decays as the charge carriers recombine or become trapped. The time resolution of these measurements are limited by the width of the laser pulse ( $3.5 \mathrm{~ns}$ full width at half maximum) and the response time of the microwave cavity ( $\sim 18 \mathrm{~ns})$. The product of the yield of free charges $(\varphi)$ and mobility of the charge carriers $\left(\sum \mu=\mu_{e}+\right.$ $\left.\mu_{h}\right)$ for $\mathrm{CA}_{-} \mathrm{C}_{4}(\langle n>=1,2,3,4,10,40)$ and PEA $\langle n\rangle=40$ are shown Figure $5(b)$. These values were calculated from the maximum change in photoconductivity, $\Delta G_{\max }$, according to equation 1 . Where, $\mathrm{I}_{0}$ is the number of photons per unit area per pulse, $\beta$ is the ratio of the inner dimensions of the microwave cell, $\mathrm{e}$ is the elementary charge, and FA is the fraction of light absorbed by the sample at the excitation wavelength.

$\varphi \sum \mu=\frac{\Delta G_{\max }}{I_{o} \beta e F_{A}}$

It is clear in Figure 5 ( $b$ and d) that the photo-conductivity of CA- $\mathrm{C}_{4}$ $\langle n\rangle=40$ is larger than the photo-conductivity of CA-C $C_{4}\langle n\rangle=1,2,3$, 4,10 . A magnified version of $\langle n\rangle=4$ and 10 is shown in Figure S13. A similar general trend is observed in the half-lifetime of the charge carriers shown in Figure 5 (c, e). The photo-conductivity and halflifetime for PEA $\langle n\rangle=40$ are also large. The low photo-conductivity and short lifetime of $\mathrm{CA}-\mathrm{C}_{4} n=1$ are similar to previous measurements on other $2 \mathrm{D}$ perovskites with the same experimental technique. ${ }^{49}$ This behaviour is explained by the large exciton binding energy of 2D perovskites, which decreases the yield of free charges $(\varphi)$ and increases the recombination. ${ }^{49}$ In the case of our CA- $C_{4}\langle n>$ $=1,2,3,4,10$ samples the photoconductivity and half-lifetime do not follow a clear increasing trend with $n$. This is contrary to what has been shown previously for another $2 \mathrm{D}$ multi-layered material. ${ }^{49} \mathrm{~A}$ probable reason for this is the presence of phases with different $n$. It can be noticed that the expected increase in photoconductivity and half-lifetime is present going from $\langle n\rangle=1$ to 2 . This fits with the XRD and absorption results of these films. Whereas the $\langle n\rangle=2$ film is mostly pure phase, for $\langle n\rangle>2$ phases with different $n$ are more clearly present. In conclusion, the half-lifetimes for the novel CA- $C_{4}$ based $2 \mathrm{D}$ multi-layered perovskite thin films with $\langle n\rangle=2,3$ and 4 are longer than for the reported butylammonium (BA) based multilayered perovskite thin films prepared with the same procedure. ${ }^{49}$ This is an encouraging result showing the potential benefit of using organic cations with an extended $\pi$-system in multi-layered perovskites.

Interestingly, the mobility of charge carriers of $\mathrm{CA}^{-C_{4}}\langle n\rangle=40$ and PEA $<n>=40$ is respectively $\sim 8 \mathrm{~cm}^{2} / \mathrm{Vs}$ and $16 \mathrm{~cm}^{2} / \mathrm{Vs}$ which is relatively high. We estimated the diffusion length of charge carriers to be $\sim 2.4 \mu \mathrm{m}$ and $\sim 4 \mu \mathrm{m}$; which largely exceed the thickness of the films $\left(0.3 \mu \mathrm{m}\right.$ for $\mathrm{CA}-\mathrm{C}_{4}<n>=40$ and $0.8 \mu \mathrm{m}$ for PEA $\left.\langle n\rangle=40\right)$. The mobility and diffusion lengths of the $P E A<n>=40$ thin films are comparable to these measured for the 3D MAPI using the same 
technique. ${ }^{27}$ The mobility of charge carriers in MAPI thin films measured by photoconductivity TRMC varies between $8-40 \mathrm{~cm}^{2} / \mathrm{Vs}$, while the diffusion length varies between 1.5 and $10 \mu \mathrm{m} .{ }^{27} \mathrm{In}$ fact, the diffusion length is similar to that of planar MAPI films $(\sim 4.1$ $\mu \mathrm{m})^{27}$ in spite of having lower charge carrier mobilities $\left(30 \mathrm{~cm}^{2} / \mathrm{Vs}\right.$ for planar MAPI thin-films). ${ }^{27}$ These relatively high mobilities and large diffusion lengths suggest that our $\mathrm{CA}-\mathrm{C}_{4}\langle n\rangle=40$ and the PEA $\langle n\rangle=$ 40 films are attractive candidates for solar cell applications. The improved electronic properties of CA- $\mathrm{C}_{4}\langle n\rangle=40$ and PEA $\langle n\rangle=40$ over CA-C $C_{4}$ films with lower values of $\langle n\rangle(\langle n\rangle=1,2,3,4,10)$ is most likely due to their quasi-3D nature. This will increase the dielectric constant in the inorganic octahedral layers and therefore decrease the exciton binding energy and recombination rate. The comparable diffusion lengths of the $\langle n>=40$ materials with MAPI films in spite of having lower mobilities, could be caused by grain boundary passivation by the carbazole and PEA molecules. These "high- $n$ " quasi-3D perovskites could actually be considered grains of $3 D$ perovskites surrounded by the organic molecules. The organic molecules passivate defects and might improve the stability and performance of the solar cells. ${ }^{27}$ We focus on high- $<n>$ materials for the preparation of solar cell devices (vide infra). The solar cell stability and performance are studied in the following sections.
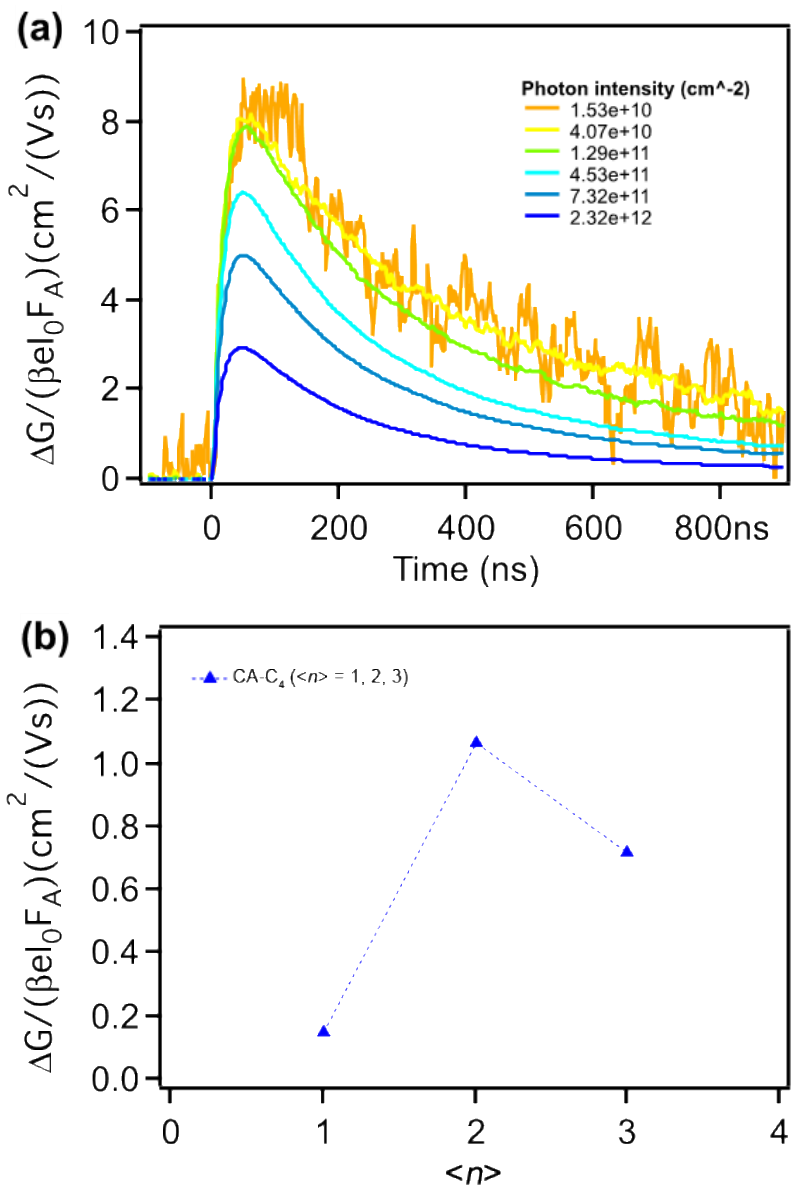
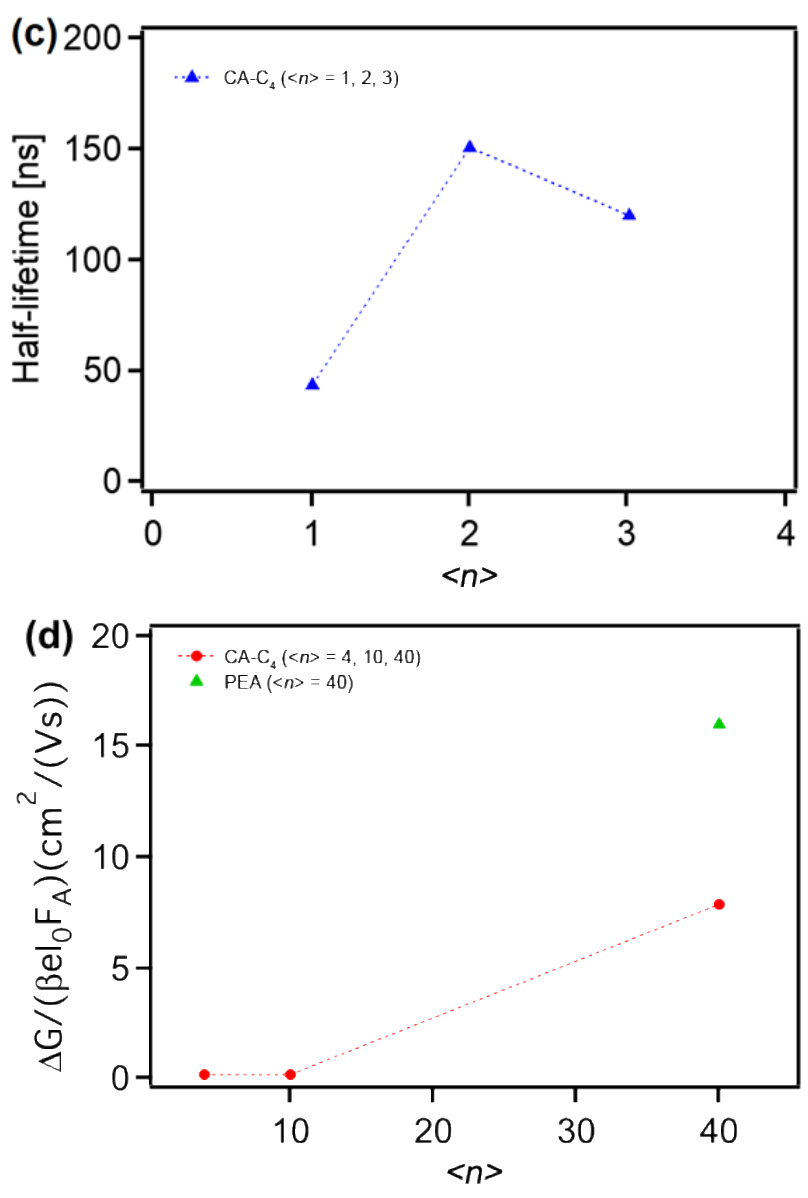


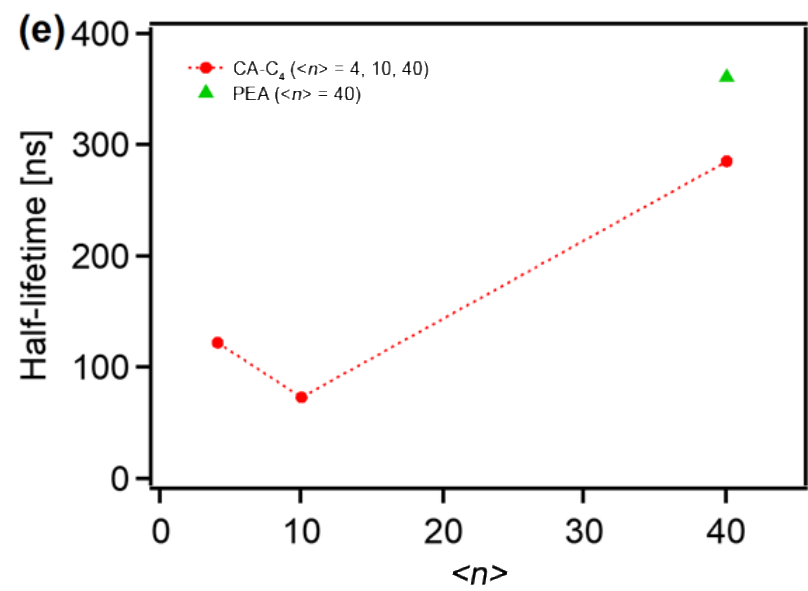

Figure 5. (a) Change of photo-conductivity as a function of time for CA- $C_{4}\langle n\rangle=40$. Excited at $633 \mathrm{~nm}$. (b) Change of photo-conductivity and (c) Half-lifetime of the charge carriers as a function of $\langle n\rangle$ for $<n>=1,2,3$ excited at $493 \mathrm{~nm}, 561 \mathrm{~nm}$ and $601 \mathrm{~nm}$, respectively. Prepared by spin coating and post-annealing at $110^{\circ} \mathrm{C}, 150{ }^{\circ} \mathrm{C}$ and $130{ }^{\circ} \mathrm{C}$, respectively. (d) Change of photo-conductivity and (e) Halflifetime of the charge carriers as a function of $\langle n\rangle$ for $\langle n\rangle=4,10,40$ excited at $633 \mathrm{~nm}$. Prepared by hot-casting at $110^{\circ} \mathrm{C}$.

\section{Environmental stability of films}

One of the objectives in the development of functional multi-layered perovskites is to benefit from their potential stability, while maintaining as much as possible the PCE associated with their parent $3 \mathrm{D}$ perovskites. The environmental stability of the novel $\langle n\rangle=40$ multi-layered perovskite featuring $\mathrm{CA}-\mathrm{C}_{4}$ was therefore evaluated by XRD over time at $77 \%$ relative humidity $(\mathrm{RH})$ in the dark at room temperature. The stability was compared to the references MAPI and the $\langle n\rangle=40$ multi-layered perovskite with PEA.

For the MAPI film, initially the monohydrate ${ }^{50}$ (Figure 6, main reflections at $\sim 8.5^{\circ}$ and $\sim 10.6^{\circ}$ ) is formed followed by slower formation of lead iodide (Figure 7, main reflection at $\sim 12.6^{\circ}$ ). In the case of $\mathrm{PEA}\langle n\rangle=40$, there is no clear sign of hydrate formation over the time of the experiment but lead iodide is slowly formed over time (Figure 8). The enhanced moisture stability of films with PEA was attributed in literature to the presence of the PEA molecules at the perovskite grain boundaries..$^{4,41}$ However, the small amount of PEA used for the $\langle n\rangle=40$ stoichiometry is clearly not sufficient to completely prevent degradation over the time period of the experiment. For the novel $\mathrm{CA}-\mathrm{C}_{4}\langle n\rangle=40$, no significant changes in the diffraction pattern can be noticed over the 62 days of the experiment (Figure 9). In Figure S4 we show that the morphology of hot-casted $\mathrm{PEA}\langle n\rangle=40$ films is very similar to that of hot-casted CA$C_{4}\langle n\rangle=40$ films, hence the enhanced stability of the CA- $C_{4}\langle n\rangle=40$ films can not be ascribed to differences in film morphology. The enhanced stability for $\mathrm{CA}-\mathrm{C}_{4}$ compared to PEA could be related to the more bulky nature of the carbazole molecules and their strong $\pi-\pi$ stacking, which could make water intrusion through the organic layer more difficult. Although only a relatively small amount ( $\sim 5 \mathrm{~mol} \%$ compared to $\mathrm{mol}_{\mathrm{MA}}+\mathrm{mol}_{\mathrm{CA}}$ ) of the large cation $\mathrm{CA}-\mathrm{C}_{4}$ is incorporated, a significantly enhanced moisture stability is obtained for this novel multi-layered perovskite material compared to the known 3D MAPI and PEA $\langle n\rangle=40$ (see supporting information, Figure S14 for optical pictures of the films). This result is a clear demonstration of the benefit on the intrinsic stability of the use of bulky cations containing extended $\pi$-systems in multi-layered perovskites.

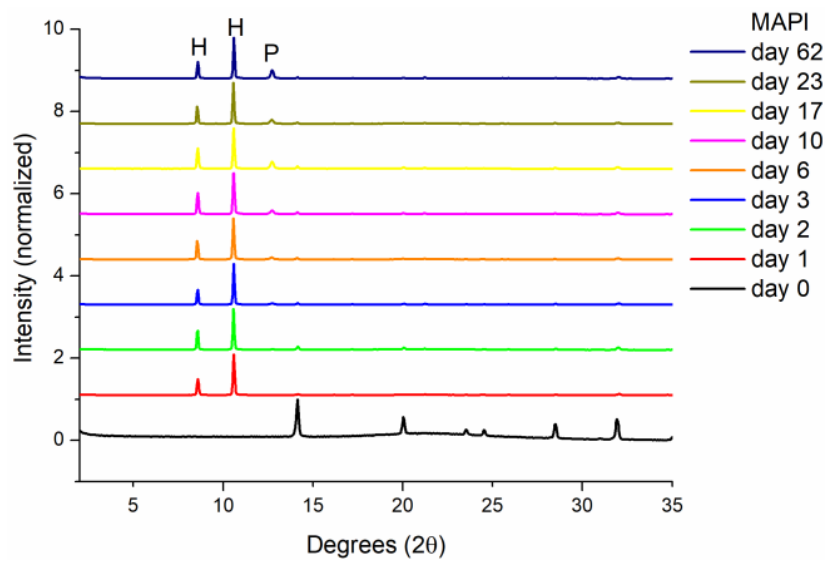

Figure 6. XRD patterns of a MAPI film hot-cast at $110^{\circ} \mathrm{C}$, measured at different times stored at $77 \% \mathrm{RH}$. The label $\mathrm{H}$ is given to the two main reflections of the monohydrate $\mathrm{MAPbl}_{3} . \mathrm{H}_{2} \mathrm{O}$ located at $\sim 8.5^{\circ}$ and $~$ $10.6^{\circ} 2 \vartheta$. The label $P$ is given to the main reflection of lead iodide located at $\sim 12.6^{\circ} 2 \vartheta$

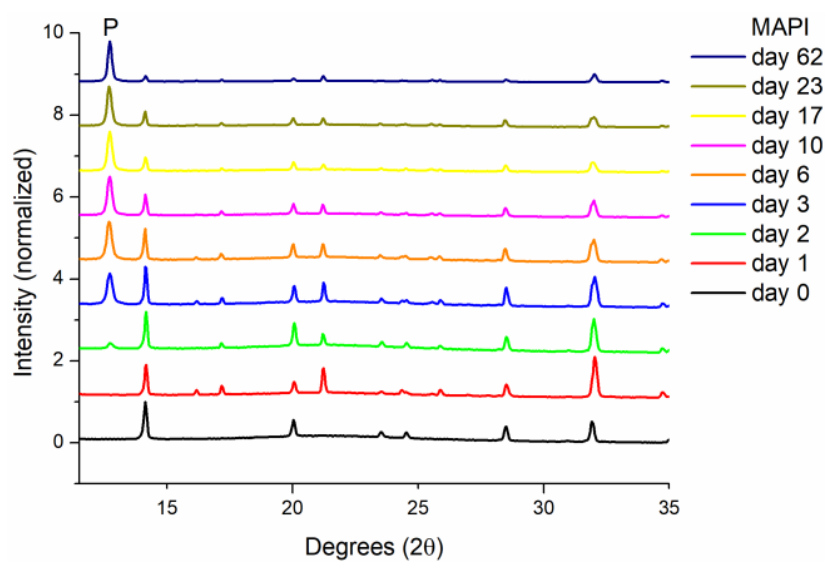

Figure 7. XRD patterns of a MAPI film hot-cast at $110^{\circ} \mathrm{C}$, measured at different times stored at $77 \% \mathrm{RH}$, showing the range of $11.5^{\circ}$ till $35^{\circ}$ 20. The label $P$ is given to the main reflection of lead iodide located at $\sim 12.6^{\circ} 2 \vartheta$.

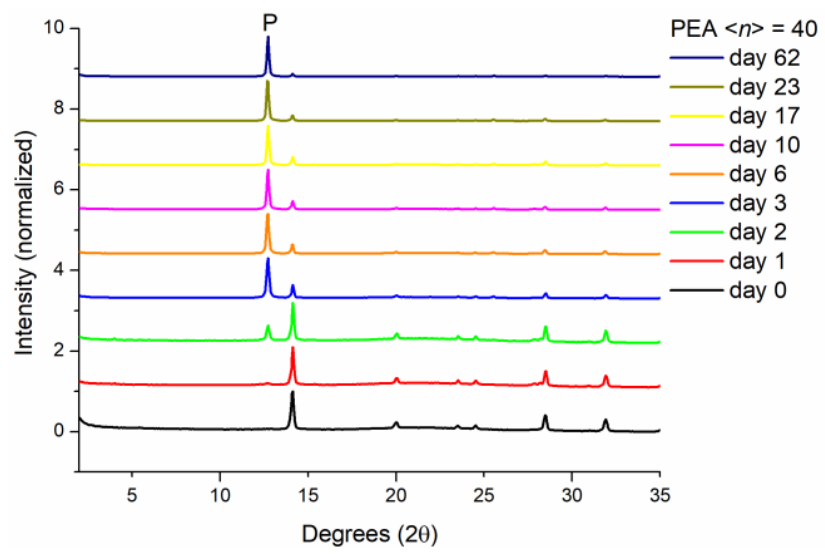

Figure 8. XRD patterns of a PEA $<n>=40$ film hot-cast at $110{ }^{\circ} \mathrm{C}$ measured at different times stored at $77 \% \mathrm{RH}$. The label $\mathrm{P}$ is given to the main reflection of lead iodide located at $\sim 12.6^{\circ} 2 \vartheta$. 


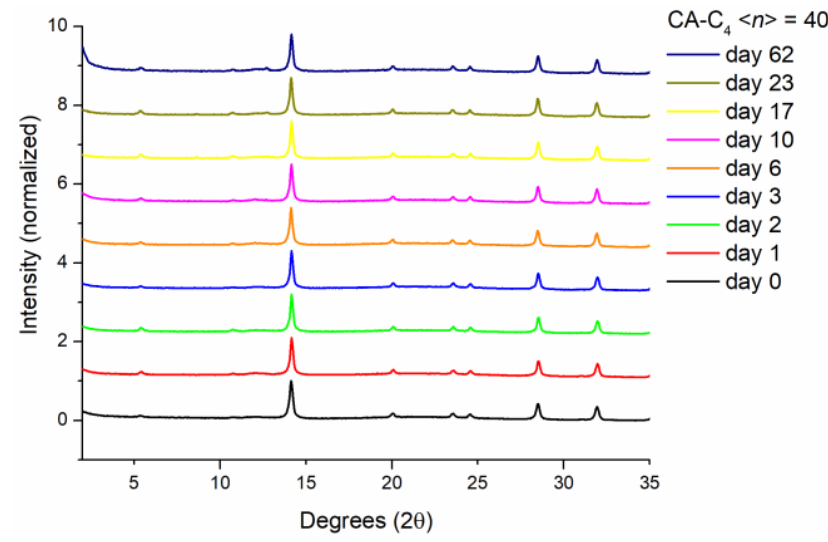

Figure 9. XRD patterns of a CA-C $C_{4}<n>=40$ film hot-cast at $110{ }^{\circ} \mathrm{C}$, measured at different times being stored at $77 \% \mathrm{RH}$.

\section{Solar cell behaviour and device stability under moisture}

The novel multi-layered perovskite material $\mathrm{CA}-\mathrm{C}_{4}\langle n\rangle=40$ was further integrated in photovoltaic devices and compared to the $3 D$ perovskite MAPI and PEA $\langle n\rangle=40$ in terms of efficiency and stability. Devices were made in an ITO/SnO $/$ perovskite/Spiro-OMeTAD/Au configuration. The perovskite films are around $200 \mathrm{~nm}$ thick, therefore the initial short circuit current $\left(\mathrm{J}_{\mathrm{sc}}\right)$ of the devices are between 12.5 and $14.5 \mathrm{~mA} / \mathrm{cm}^{2}$ (Figure 10b). The PCEs obtained for the devices are moderate (Table 6). We deliberately chose to use the basic 3D perovskite MAPI as the parent material of our $\mathrm{CA}-\mathrm{C}_{4}\langle n\rangle=$ 40 and not the advanced mixed cations/mixed halides 3D perovskites which give higher PCE in devices as our main goal here was only a comparative study to evaluate directly the effect of using our carbazole derivative. Therefore we kept the material system as simple as possible for this first proof-of-concept.

The devices were stored in $77 \% \mathrm{RH}$ air for $264 \mathrm{~h}$ in the dark. The colour of the carbazole $\langle n\rangle=40$ perovskite films stays dark, while MAPI and PEA $\langle n\rangle=40$ films turn transparent (Figure S15). The degradation of the active layer leads to a drastic decrease of the Jsc for MAPI and PEA $<n>=40$ devices (Figure 10b). In contrast, the Jsc of carbazole $\langle n\rangle=40$ devices only slightly decreases. Open circuit voltages of carbazole $\langle n\rangle=40$ devices are also more stable than those of MAPI and PEA $\langle n\rangle=40$ devices (Figure 10c). As a result, carbazole $\langle n\rangle=40$ devices maintain more than $80 \%$ of their initial efficiencies, while MAPI and PEA $\langle n\rangle=40$ devices lose more than 60 $\%$ of their initial efficiencies (Figure 10a and Table 6). These results reveal that adding a small percentage of the carbazole derivative to the perovskite precursor solutions can remarkably enhance the moisture stability of devices and that the stabilizing effect of the carbazole derivatives significantly outperforms that of PEA.

Table 6. Initial and final PCE (with standard deviation) of the devices stored at $77 \% \mathrm{RH}$.

\begin{tabular}{|l|c|c|}
\hline Active layer & Initial PCE (\%) & Final PCE (\%) \\
\hline CA-C $_{4}<n>=40$ & $6.6 \pm 0.2$ & $5.4 \pm 0.2$ \\
\hline PEA $<n>=40$ & $7.6 \pm 0.3$ & $2.7 \pm 0.3$ \\
\hline MAPI & $8.0 \pm 0.2$ & $2.9 \pm 0.2$ \\
\hline
\end{tabular}

(a)

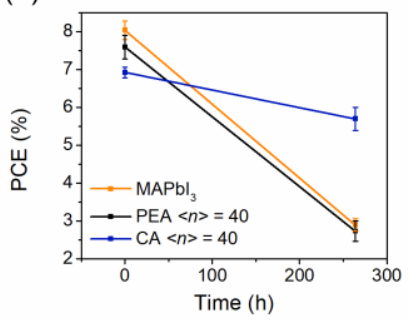

(c)

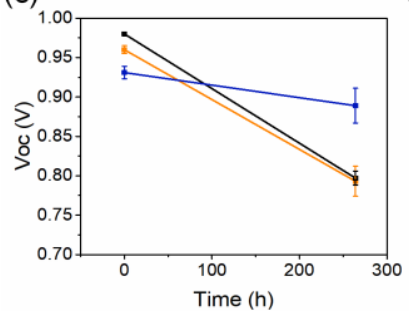

(b)

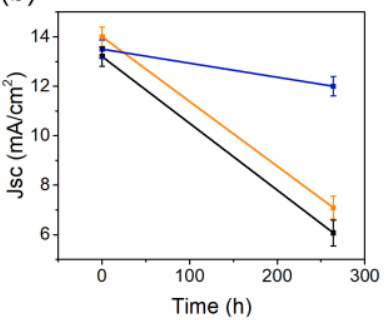

(d)

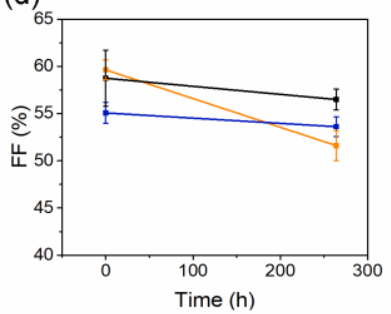

Figure 10. Changes of device metrics after being stored in $77 \% \mathrm{RH}$ air, in the dark, for $264 \mathrm{~h}$. Average value and standard deviation shown on each data point are obtained from 12 devices.

\section{Conclusions}

In summary, multi-layered perovskites templated with carbazole derivatives were synthesized. The absorption and emission characteristics could be tuned by variation of the number of inorganic layers $(n)$ in the perovskite structure. Interestingly, films of low- $n$ carbazole containing perovskites showed high photoconductivity half-lifetimes in comparison to films of established low- $n$ multi-layered perovskites. Higher- $n$ $(<n>=40)$ multi-layered perovskite films possess charge carrier diffusion lengths comparable to MAPI thin films. Solar cells containing these materials have comparable efficiencies to our MAPI and phenethylammonium (PEA) $<n>=40$ reference devices. Furthermore, moisture stability tests were performed both at the material and device levels. These tests showed that adding a small percentage of the carbazole derivative significantly enhances the moisture stability of the perovskite material and of the solar cells, compared to their PEA counterparts. The promising results obtained with carbazole as a first example of a large organic cation containing an extended $\pi$-system in multi-layered perovskites open the way to other systems in which similar tailored will be incorporated. Future work includes applying this concept to state-of-the-art mixed cation/mixed halide 3D perovskite formulations to combine the higher PCE with enhanced stability.

\section{Conflicts of interest}

There are no conflicts to declare.

\section{Acknowledgements}

We thank Nadège Marchal for the work she did during her internship at the HyMaD group. R.H. is a special research fund (BOF) Doctoral (PhD) student at UHasselt/IMO. W.T.M.V.G. is an SB PhD fellow at FWO (project number $1 \mathrm{~S} 17516 \mathrm{~N}$ ), the FWO is acknowledged for the funding of the research. The PVopMaat 
project funded by Interreg Vlaanderen-Nederland (01.01.201631.12.2018) and the M-ERA.NET project called PROMISES (01.07.2016-30.06.2018) are acknowledged for their funding. The research leading to these results in the Delft University of Technology has received funding from the European Research Council Horizon 2020 ERC Grant Agreement no. 648433. This work has been carried out in the context of the Solliance network (www.solliance.eu), from which imec, UHasselt and TUDelft are members. Additionally, imec, KU Leuven and UHasselt are partners in the EnergyVille consortium (http://www.energyville.be/en/about-energyville).

\section{References}

National Renewable Energy Laboratory, Best Research-Cell Efficiencies,

https://www.nrel.gov/pv/assets/images/efficiency-

chart.png, (accessed 10 July 2017).

Z. Wang, Z. Shi, T. Li, Y. Chen and W. Huang, Angew. Chemie, 2017, 56, 1190-1212. I. C. Smith, E. T. Hoke, D. Solis-lbarra, M. D. McGehee and H. I. Karunadasa, Angew. Chemie, 2014, 126, 11414-11417. D. S. Lee, J. S. Yun, J. Kim, A. M. Soufiani, S. Chen, Y. Cho, X Deng, J. Seidel, S. Lim, S. Huang and A. W. Y. Ho-Baillie, ACS Energy Lett., 2018, 3, 647-654. H. Zheng, G. Liu, L. Zhu, J. Ye, X. Zhang, A. Alsaedi, T. Hayat, X. Pan and S. Dai, Adv. Energy Mater., 2018, 8, 1800051. X. Zhang, X. Ren, B. Liu, R. Munir, X. Zhu, D. Yang, J. Li, Y. Liu, D.-M. Smilgies, R. Li, Z. Yang, T. Niu, X. Wang, A. Amassian, K. Zhao and S. (Frank) Liu, Energy Environ. Sci., 2017, 10, 2095-2102.

C. M. M. Soe, W. Nie, C. C. Stoumpos, H. Tsai, J.-C. Blancon, F. Liu, J. Even, T. J. Marks, A. D. Mohite and M. G. Kanatzidis, Adv. Energy Mater., 2018, 8, 1700979. J.-C. Blancon, H. Tsai, W. Nie, C. C. Stoumpos, L. Pedesseau, C. Katan, M. Kepenekian, C. M. M. Soe, K. Appavoo, M. Y. Sfeir, S. Tretiak, P. M. Ajayan, M. G. Kanatzidis, J. Even, J. J. Crochet and A. D. Mohite, Science (80-. )., 2017, 355, 12881292. J.-F. Liao, H.-S. Rao, B.-X. Chen, D.-B. Kuang and C.-Y. Su, J. Mater. Chem. A, 2017, 5, 2066-2072. Mater., 2017, 1702073.

12 L. Etgar, Energy Environ. Sci., 2018, 11, 234-242.

13 B. Saparov and D. B. Mitzi, Chem. Rev., 2016, 116, 45584596.

14 J. V. Passarelli, D. J. Fairfield, N. A. Sather, M. P. Hendricks, H. Sai, C. L. Stern and S. I. Stupp, J. Am. Chem. Soc., 2018, jacs.8b03659.

15 M. I. Saidaminov, O. F. Mohammed and O. M. Bakr, ACS Energy Lett., 2017, 2, 889-896.

16 Y. Chen, Y. Sun, J. Peng, W. Zhang, X. Su, K. Zheng, T. Pullerits and Z. Liang, Adv. Energy Mater., 2017, 7, 1700162. L. N. Quan, M. Yuan, R. Comin, O. Voznyy, E. M. Beauregard, S. Hoogland, A. Buin, A. R. Kirmani, K. Zhao, A. Amassian, D.
H. Kim and E. H. Sargent, J. Am. Chem. Soc., 2016, 138, 2649-2655.

L. lagher and L. Etgar, ACS Energy Lett., 2018, 3, 366-372.

J. Rodríguez-Romero, B. C. Hames, I. Mora-Seró and E. M. Barea, ACS Energy Lett., 2017, 2, 1969-1970.

B.-E. Cohen, M. Wierzbowska and L. Etgar, Sustain. Energy Fuels, 2017, 1, 1935-1943.

O. Nazarenko, M. R. Kotyrba, M. Wörle, E. Cuervo-Reyes, S. Yakunin and M. V. Kovalenko, Inorg. Chem., 2017, 56, 11552-11564.

A. H. Proppe, R. Quintero-Bermudez, H. Tan, O. Voznyy, S. O. Kelley and E. H. Sargent, J. Am. Chem. Soc., 2018, 140, 2890-2896.

J. V. Grazulevicius, P. Strohriegl, J. Pielichowski and K. Pielichowski, Prog. Polym. Sci., 2003, 28, 1297-1353.

M. Era, T. Kobayashi, K. Sakaguchi, E. Tsukamoto and Y. Oishi, Org. Electron., 2013, 14, 1313-1317.

M. Era, T. Yasuda, K. Mori, N. Tomotsu, N. Kawano, M. Koshimizu and K. Asai, J. Nanosci. Nanotechnol., 2016, 16, 3159-3167.

T. J. Savenije, A. J. Ferguson, N. Kopidakis and G. Rumbles, J. Phys. Chem. C, 2013, 117, 24085-24103.

E. M. Hutter, G. E. Eperon, S. D. Stranks and T. J. Savenije, J. Phys. Chem. Lett., 2015, 6, 3082-3090.

D. H. Cao, C. C. Stoumpos, O. K. Farha, J. T. Hupp and M. G. Kanatzidis, J. Am. Chem. Soc., 2015, 137, 7843-7850.

M. Yuan, L. N. Quan, R. Comin, G. Walters, R. Sabatini, O. Voznyy, S. Hoogland, Y. Zhao, E. M. Beauregard, P. Kanjanaboos, Z. Lu, D. H. Kim and E. H. Sargent, Nat. Nanotechnol., 2016, 11, 1-27.

Q. Shang, Y. Wang, Y. Zhong, Y. Mi, L. Qin, Y. Zhao, X. Qiu, X. Liu and Q. Zhang, J. Phys. Chem. Lett., 2017, 8, 4431-4438. J. Liu, J. Leng, K. Wu, J. Zhang and S. Jin, J. Am. Chem. Soc., 2017, 139, 1432-1435.

F. Barka-Bouaifel, K. Makaoui, P.-Y. Jouan, X. Castel, N. Bezzi, R. Boukherroub and S. Szunerits, RSC Adv., 2012, 2, 12482.

A. Vassilakopoulou, D. Papadatos, I. Zakouras and I. Koutselas, J. Alloys Compd., 2017, 692, 589-598.

W. Peng, J. Yin, K. Ho, O. Ouellette, M. De Bastiani, B. Murali, O. El Tall, C. Shen, X. Miao, J. Pan, E. Alarousu, J. He, B. S. Ooi, O. F. Mohammed, E. Sargent and O. M. Bakr, Nano Lett., 2017, 17, 4759-4767.

X. Gan, O. Wang, K. Liu, X. Du, L. Guo and H. Liu, Sol. Energy Mater. Sol. Cells, 2017, 162, 93-102.

W. Nie, H. Tsai, R. Asadpour, J.-C. Blancon, A. J. Neukirch, G. Gupta, J. J. Crochet, M. Chhowalla, S. Tretiak, M. A. Alam, H.-L. Wang and A. D. Mohite, Science (80-. )., 2015, 347, 522-525.

H. Tsai, W. Nie, J.-C. Blancon, C. C. Stoumpos, R. Asadpour, B. Harutyunyan, A. J. Neukirch, R. Verduzco, J. J. Crochet, S. Tretiak, L. Pedesseau, J. Even, M. A. Alam, G. Gupta, J. Lou, P. M. Ajayan, M. J. Bedzyk, M. G. Kanatzidis and A. D. Mohite, Nature, 2016, 536, 312-316.

A. Sharenko and M. F. Toney, J. Am. Chem. Soc., 2016, 138, 463-470.

39 R. A. Kerner, L. Zhao, Z. Xiao and B. P. Rand, J. Mater. Chem. A, 2016, 4, 8308-8315. 
40 J. C. Hamill, J. Schwartz and Y.-L. Loo, ACS Energy Lett., 2018, 3, 92-97.

41 N. Li, Z. Zhu, C.-C. Chueh, H. Liu, B. Peng, A. Petrone, X. Li, L. Wang and A. K.-Y. Jen, Adv. Energy Mater., 2017, 7, 1601307.

42 K. Du, Q. Tu, X. Zhang, Q. Han, J. Liu, S. Zauscher and D. B. Mitzi, Inorg. Chem., 2017, 56, 9291-9302.

43 M. E. Kamminga, H.-H. Fang, M. R. Filip, F. Giustino, J. Baas, G. R. Blake, M. A. Loi and T. T. M. Palstra, Chem. Mater., 2016, 28, 4554-4562.

44 B. Traore, L. Pedesseau, L. Assam, X. Che, J.-C. Blancon, H. Tsai, W. Nie, C. C. Stoumpos, M. G. Kanatzidis, S. Tretiak, A. D. Mohite, J. Even, M. Kepenekian and C. Katan, ACS Nano, 2018, 12, 3321-3332.

45 C. C. Stoumpos, D. H. Cao, D. J. Clark, J. Young, J. M. Rondinelli, J. I. Jang, J. T. Hupp and M. G. Kanatzidis, Chem. Mater., 2016, 28, 2852-2867.

46 X. Wu, M. T. Trinh, D. Niesner, H. Zhu, Z. Norman, J. S. Owen, O. Yaffe, B. J. Kudisch and X.-Y. Zhu, J. Am. Chem. Soc., 2015, 137, 2089-2096.

47 I. Neogi, A. Bruno, D. Bahulayan, T. W. Goh, B. Ghosh, R. Ganguly, D. Cortecchia, T. C. Sum, C. Soci, N. Mathews and S. G. Mhaisalkar, ChemSusChem, 2017, 10, 3765-3772.

48 M. D. Smith, A. Jaffe, E. R. Dohner, A. M. Lindenberg and H. I. Karunadasa, Chem. Sci., 2017, 8, 4497-4504.

49 M. C. Gélvez-Rueda, E. M. Hutter, D. H. Cao, N. Renaud, C. C. Stoumpos, J. T. Hupp, T. J. Savenije, M. G. Kanatzidis and F. C. Grozema, J. Phys. Chem. C, 2017, 121, 26566-26574.

50 A. M. A. Leguy, Y. Hu, M. Campoy-Quiles, M. I. Alonso, O. J. Weber, P. Azarhoosh, M. van Schilfgaarde, M. T. Weller, T. Bein, J. Nelson, P. Docampo and P. R. F. Barnes, Chem. Mater., 2015, 27, 3397-3407.

51 R. Quintero-Bermudez, A. Gold-Parker, A. H. Proppe, R. Munir, Z. Yang, S. O. Kelley, A. Amassian, M. F. Toney and E. H. Sargent, Nat. Mater., 2018, 17, 900-907. 